\title{
Molecular diagnostic of Ureaplasma urealyticum presence and tetracycline resistance in urine samples
}

\author{
Mihaela Laura Vica ${ }^{1}$, Horea Vladi Matei ${ }^{1 *}$, \\ Agnes Katona ${ }^{1}$, Aida Puia ${ }^{2}$, Cosmin Adrian Teodoru ${ }^{3}$ \\ 1. Department of Cell and Molecular Biology, "Iuliu Hatieganu” University of Medicine and \\ Pharmacy, Romania \\ 2. Department of Family Medicine, "Iuliu Hatieganu” University of Medicine and Pharmacy, Cluj- \\ Napoca, Romania \\ 3. Clinical Surgical Department, Faculty of Medicine, "Lucian Blaga” University of Sibiu, Romania
}

\begin{abstract}
Sexually transmitted infections (STIs) are among the most common infections in Romania. Infection with Ureaplasma urelyticum is one of the major causes of STIs and can cause serious complications. Although tetracycline is the drug commonly used to treat infections caused by U. urealyticum, several studies indicate the emergence and rapid development of strains resistant to these antibiotics in the United States or Europe. Tetracycline resistance in bacteria is encoded by a number of different genetic determinants but in mycoplasmas the only tetracycline resistance determinant that has been reported is the tetM gene. Tetracycline resistance among Ureaplasma spp. is associated with the presence of the horizontally acquired tetM resistance gene. Our study on bacterial DNA aimed to determine the presence of tetracycline-resistant $U$. urealyticum strains, by identifying the presence of the tetM gene. We used first void urine samples from 622 STI-suspected subjects. DNA was extracted, purified and amplified via PCR for the simultaneous detection of 6 STIs. 68 patients were diagnosed with U. urealyticum. DNA obtained from these samples was amplified using the tetM gene and U. urealyticum - specific urease gene primers. The urease gene was amplified in all samples, confirming the presence of U. urealyticum. The tetM gene was amplified in 2 samples considered tetracycline-resistant strains. The study confirmed the presence of U. urealyticum strains resistant to tetracycline in Romania. The employed technique can produce quick results both for $U$. urealyticum detection and determination of its resistance to tetracycline using a single easy-to-collect biological sample.
\end{abstract}

Keywords: PCR, Ureaplasma urelyticum, tetracycline-resistant, tetM gene, urease gene

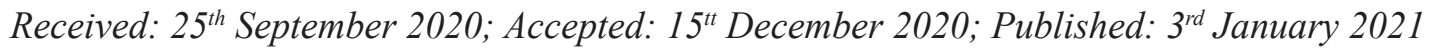

\footnotetext{
* Corresponding author: Horea Vladi Matei, Department of Cell and Molecular Biology, "Iuliu Haţieganu" University of Medicine and Pharmacy, 8 Victor Babes St., 400 012, Cluj-Napoca,

Romania. E-mail: horea_matei@yahoo.com
} 


\section{Introduction}

Sexually transmitted infections (STIs) are caused by a wide variety of bacteria, viruses and parasites intraspecifically transmitted mainly by vaginal, anal, or oral sexual contact. According to the statistics of the Centers for Disease Control and Prevention (CDC), more than 1 million STIs are daily acquired worldwide and the majority of STIs have no or only mild symptoms that may not be recognized as an STI (1). STI dissemination in the general population is an important health problem in Romania, amplified by the absence of a national screening program (2). A relatively high percentage of youngsters with risky sexual behavior and insufficient knowledge regarding STI consequences poses additional risks towards a population-wide disease spreading (3). Ureaplasma urealyticum (belonging to family Mycoplasmataceae, order Mycoplasmatales, class Mollicutes) is among the most common STI-causing bacteria. Lack of a rigid cell wall prevents reactivity with Gram staining and do not respond to antibiotics targeting bacterial cell walls (i.e., $\beta$-lactams and glycopeptide antibiotics) (4).

$U$. urealyticum can be found in the cervix or vagina (or both) of $40 \%-80 \%$ of the sexually mature asymptomatic women (5), but has also been linked to nongonococcal urethritis (NGU), arthritis, meningitis, chorioamnionitis, and preterm labor $(6,7)$. Patients suffering from clinical chorioamnionitis may deliver prematurely. U. urealyticum is often isolated from preterm infants, stillborn, and spontaneously aborted fetuses (5). Most laboratories lack the capability to cultivate and test for sensitivity Ureaplasma spp. and Mycoplasma spp., as they are fastidious cell wallfree bacteria. Even if cultured, a distinction between $U$. urealyticum and Ureaplasma parvum is difficult to be made and results are often mistakenly reported (8).
Polymerase chain reaction (PCR) is a molecular biology method presenting high sensitivity and rapidity compared with culture-based and other traditional methods employed in STI diagnosis. However, inappropriate reporting in regard to species differentiation can occur in qualitative PCR assays as well $(8,9)$.

The three classes of antibiotics active against Ureaplasma spp. are the quinolones, tetracyclines and macrolides (10). Of these, tetracycline is the drug most commonly employed in the treatment of $U$. urealyticum infections (11). The first tetracycline-resistant $U$. urealyticum strain was isolated in 1974 in British Columbia (12). An American study conducted in 1981 reported a $6-10 \%$ prevalence of these resistant strains (13), while another one in 1986 revealed that more than $15 \%$ of $U$. urealyticum strains isolated from STD patients were resistant to tetracycline (14). On the other hand, a frequency of only $2-3 \%$ tetracycline-resistant $U$. urealyticum strains was observed in France during the 1992-2002 interval (15). However, an increased prevalence of tetracycline and fluoroquinolone resistance in Ureaplasma spp. has recently been suggested in Europe (16).

In bacteria, tetracycline resistance is encoded by a number of genetic determinants. The tet $O$ and tet $M$ genes have been found in Gram-negative and Gram-positive bacteria, and the latter is known to be transferable between the two groups (17). TetM is the only tetracycline resistance determinant reported so far in mycoplasmas (18). In these bacteria, a high level of acquired resistance to tetracyclines is associated with the presence of the tetM gene (19) and PCR amplification identified tet $M$ to be present in the tetracycline-resistant isolates (20). Our study aimed to identify $U$. urealyticum in urine samples using the PCR technique and to determine its susceptibility to tetracycline based on the presence or absence of the $t e t M$ gene. 


\section{Material and methods}

\section{Patients and specimens}

Between January 2014 and September 2019 a number of 622 subjects aged 17 to 75 years, including patients presenting STI symptoms (genital discharge, dysuria, fever or abdominal pain) and asymptomatic individuals involved in unprotected sex with multiple partners were enrolled in this study approved by the Ethics Committee of the "Iuliu Haţieganu" University of Medicine and Pharmacy in Cluj-Napoca (no. 146/15.04.2014). No patient was subjected to antibiotic treatment two weeks prior to inclusion in the study.

Samples of 30 to $50 \mathrm{~mL}$ first void urine were collected in sterile polypropylene containers during early morning hours, provided the patients had not urinated for the preceding 4 hours.

\section{DNA extraction}

Aliquots of urine samples were centrifuged for $15 \mathrm{~min}$ at $15,000 \mathrm{~g}$ and the resulting pellet was re-suspended in phosphate-buffered saline (PBS). MasterPure $^{\mathrm{TM}}$ Complete DNA and RNA Purification Kit (EPICENTRE Biotechnologies, USA) were used for DNA extraction and purification according to supplier recommendations. The DNA was suspended in nucleotide-free water.

DNA concentration and purity were determined by nano-photometer readings against a reference nucleotide-free water. DNA purification sequence was repeated whenever purity was inappropriate.

\section{DNA amplification for $U$. urealyticum detec- tion}

Three $\mu 1$ of DNA extracts were amplified on a DNA thermal-cycler with a Seeplex ${ }^{\circledR}$ STD6 ACE Detection (Seegene, Korea) kit in a total volume including $17 \mu \mathrm{l}$ PCR mix with $5 x$ STD6ACE PM primers containing primer pairs for Chlamydia trachomatis, Neisseria gonorrhoeae, Trichomonas vaginalis, U. urealyticum, Mycoplasma genitaliumi, and Mycoplasma hominis, a primer pair for internal control and an internal control template.

PCR was initiated with a 15 min denaturation step at $94^{\circ} \mathrm{C}$ and a $10 \mathrm{~min}$ extension-step at $72^{\circ} \mathrm{C}$ followed the 40 amplification cycles (each including a $30 \mathrm{~s}$ denaturation step at $94^{\circ} \mathrm{C}$, a $90 \mathrm{~s}$ annealing step at $63^{\circ} \mathrm{C}$ and a 90 s chain elongation step at $72^{\circ} \mathrm{C}$ ). PCR products were separated using a $2 \%$ agarose gel stained with ethidium bromide.

\section{DNA amplification for $U$. urealyticum confir- mation and tetracycline susceptibility}

DNA extracted from $U$. urealyticum positive samples was amplified using U. urealyticum specific urease gene and tet $M$ gene primers designed using a modified version of previously published sequences $(10,18,21)$. The primer sequences are presented in Table 1. No reference tetracycline resistance strains were available for positive control.

Amplification was carried out in a total volume of $50 \mu \mathrm{l}$ including $2 \mu \mathrm{l}$ DNA extract, $25 \mu \mathrm{l} \mathrm{My}$ -

Table 1. The sequences of the tetM and urease genes primers

\begin{tabular}{lccc}
\hline Primer & Sequence & Product length & GC\% \\
\hline tet $M$ & TTATCAACGGTTTATCAGG & 398 & \\
Forward & & & 49.74 \\
Reverse & & & 52.07 \\
& CGTATATATGCAAGACGTTG & 429 & \\
frease gene & & & 56.79 \\
Reverse & ACGACGTCCATAAGCAACT & & 55.05 \\
\hline
\end{tabular}


Taq $^{\mathrm{TM}}$ Red Mix (Bioline, UK) mixed with $4 \mu \mathrm{l}$ primers containing primer pairs for tet $M$ and urease genes, and $19 \mu \mathrm{l}$ water $\left(\mathrm{ddH}_{2} \mathrm{O}\right)$.

Based on several optimization attempts, the protocol employed a $60 \mathrm{~s}$ denaturation step at $95^{\circ} \mathrm{C}$ and 35 amplification cycles including a $15 \mathrm{~s}$ denaturation step at $95^{\circ} \mathrm{C}$, a $15 \mathrm{~s}$ annealing step at $58^{\circ} \mathrm{C}$ and a $10 \mathrm{~s}$ extension step at $72^{\circ} \mathrm{C}$. The amplicons were separated via gel electrophoresis using $2 \%$ agarose gel (see Figure 1).

\section{Results}

\section{$U$. urealyticum detection in urine samples}

Two hundred of the 622 subjects included in the study were positive for various STIs, 68 of these ( $10.93 \%$ of the total patients) presenting the corresponding $U$. urealyticum DNA (the second most frequently detected bacterium after C. trachomatis), 34 of these patients presented multiple infections.

\section{Detection of $U$. urealyticum tetracycline sus- ceptibility}

The urease gene was amplified in all the samples collected from $U$. urealyticum positive patients. The tet $M$ gene was amplified in 2 samples ac- counting for tetracycline-resistant strains (e.g. sample S2 in Figure 1).

\section{Discussion}

In recent years, Ureaplasma spp. were recognized as pathogens in numerous clinical presentations. The large number of patients positive for U. urealyticum (34\% of the positive patients) identified in our study is in accordance with literature data and the conclusions of our previous studies $(7,22,23)$ indicating that infection with this bacterium remains one of the major causes of STIs in Romania.

An accurate diagnosis is needed in order to prevent severe complications and to control transmission, especially in asymptomatic infections. As bacteriological cultures allow further testing of antibiotic susceptibility, the technique is useful in detecting susceptibility to antibiotics. However, in contrast to other prokaryotes, currently there are no Clinical and Laboratory Standards Institute (CLSI) recommended guidelines for the susceptibility testing of ureaplasma. Agar disk diffusion is unsuitable for such purpose because of the small colony sizes and prolonged growth periods (24).

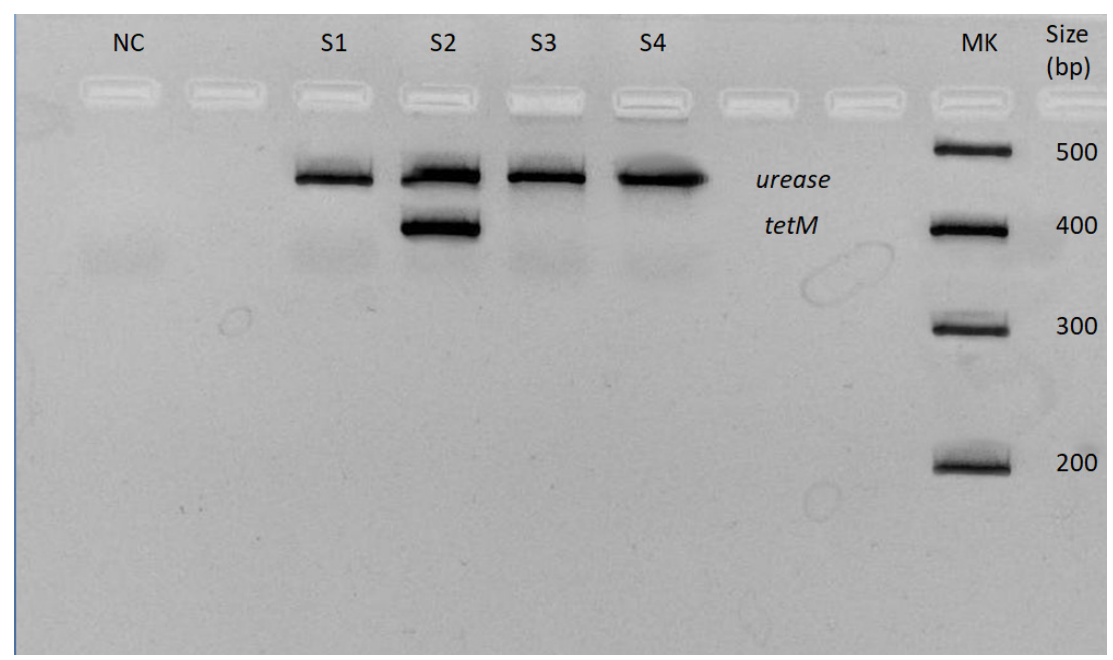

Fig. 1. Electrophoretic analysis of amplicons by PCR with specific primers for urease and tetM genes. NC: negative control, S1-S4: samples, MK: molecular weight marker, bp: base pairs 
Recent years have seen an extensive usage of nucleic acid amplification tests (NAATs), for carrier detection in particular. These genetic tests enable the establishing of a diagnosis for bacterial STIs with a sensitivity of up to $99 \%$. Other studies have also argued that the PCR technique is more sensitive, accurate and rapid compared with classical methods $(9,25,26)$. NAAT testing was also proved to be efficient in typing $U$. urealyticum strains including non-cultured specimens. For detection, we employed a high specificity/ sensitivity multiplex PCR kit (Seeplex ${ }^{\circledR}$ STD6 ACE Detection) able to detect the presence of several STI pathogens in the same sample, useful since these pathogens often associate and may present similar symptoms. As a result, in our 200 positive samples we found 46 associations of two to five STI pathogens, 34 of them involving U. urealyticum. Faster detection of $U$. urealyticum via PCR $(<24$ h) compared with traditional cultures (2-5 days) is particularly important in the case of very low birth-weight infants.

Another advantage of the technique is the use of first urine jet samples as DNA source for STI detection. Urine collection is less invasive compared to the harvesting of vaginal or urethral secretions, an aspect previously reported to have influenced a significant number of subjects to avoid STI identification tests (27).

Although Ureaplasma have been recognized as two separate species since 2000, species discrimination is still problematic, partly due to culture-based commercial kits. In some instances Ureaplasma spp. are reported as U. urealyticum by default due to historical taxonomic reasons, negatively impacting our understanding of the influence of the two species in the clinical outcome and the distribution of resistant species (16). A recent systemic review and meta-analysis by Zhang et al. (2014) has supported the idea that $U$. urealyticum contributes to the development of NGU, whereas $U$. parvum does not (28). To confirm the presence of $U$. urealyticum in the samples initially detected as positive for this bacterium, we determined the presence of the urease gene in all these samples. The urease structural gene from $U$. urealyticum contains unique sequences that are not present in other mycoplasmas (29). The urease gene was amplified in all the samples collected from $U$. urealyticum positive patients, confirming the accuracy of both PCR methods employed in the study (see Figure 1).

Initially found in streptococci, the tet $M$ gene often located on a conjugative transposon confers high-level resistance. Literature data suggest that tet $M$ is widely disseminated in the urogenital flora. This is similar to the previously documented spread of resistance genes from the Enterobacteriaceae to unrelated gram-negative genera (30). The tet $M$ class of determinants appears to have a wide host range, and since this determinant can be transferred by transformation or conjugation, in time, other species and genera are susceptible to acquire it $(31,32)$.

Tetracyclines are the first-line treatment of infections caused by Ureaplasma spp., to which antibiotic resistance is continuously increasing (11). Tetracycline resistance is well characterized among Ureaplasma spp. and is associated with the presence of the horizontally acquired tet $M$ resistance gene that provides ribosomal protection $(21,33)$. A large percentage of microorganisms containing the tet $M$ gene provide conditions for the transfer of the determinant to mycoplasma cells. Dystrophic changes in the urogenital mucosa and desquamation of the epithelium also facilitate the adhesion of microorganisms, mycoplasmas in particular (34).

A study screened the DNA isolated via PCR from 130 Ureaplasma spp. isolates for the presence of the tet $M$ gene and identified three positive strains $(2.3 \%)$. In contrast, broth culture screening for tetracycline resistance identified only two of these isolates. It therefore appears that screening for the presence of the tet $M$ gene 
is less likely to miss resistant isolates than broth microdilution methods employed in determining tetracycline resistance (10). A 2012 study performed on 66 strains of Ureaplasma spp. revealed that all tetracycline-resistant strains contained $397 \mathrm{bp}$ regions of the tet $M$ and the int-Tn genes (24). Another study concluded that $U$. urealyticum strains considered to be tetracycline sensitive were also found to lack tetM (18). According to Dégrange et al. (2008), phenotypically susceptible isolates bearing the tet $M$ gene should be considered and reported as resistant, despite the lack of data regarding the behavior of the microorganism during in vivo therapy (15). As clinicians tend to focus on the practical effects of the treatment they recommend, disregarding genetic evidence of antibiotic resistance, we chose to determine the presence of the tetM gene in order to observe the tetracycline resistance of the identified strains.

In our study we determined a percentage of $2.94 \%$ strains resistant to tetracycline that presented the tet $M$ gene. A French study conducted from 1999 to 2002 reported high $(>80 \%)$ sensitivity rates to tetracycline (15), while in a 4-year-study (2012-2015) in central Greece the presence of the tet $M$ gene was not detected in 76 positive cases of Ureaplasma spp., the provided explanation being that in this region doxycycline administration remains the first therapeutic option unless special medical circumstances dictate otherwise (35). A certain increase $(7.5 \%)$ in tetracycline resistance among Ureaplasma spp. was observed in a 2010-2015 French study on 831 isolates (19). The number of tetracycline-resistant strains determined in our study $(<10 \%)$ is thus consistent with several European studies $(15,19,35)$.

This is a reassuringly low resistance level compared with other international reports, especially from outside Europe. High levels of tetracycline resistance $(73 \%)$ were documented in a South African study, but speciation indicated that $U$. parvum was the predominant Ureaplasma spp. conferring antimicrobial resistance (36). A Cuban study reported that $31 \%$ of the analyzed $U$. urealyticum strains were resistant to tetracycline (37). Another research in Northern Greece on 100 isolates of Ureaplasma spp. found $14.3 \%$ tetM-positive isolates belonging to $U$. urealyticum (38). A very recent Tunisian study on 101 molecularly typed Ureaplasma spp. clinical strains detected $37.62 \%$ tetracycline-resistant isolates. In contrast to such reduced susceptibility to tetracycline, Ureaplasma spp. strains exhibited an extremely high sensitivity to doxycycline (39).

Study limitations include the relatively short period of time covered in this research and the low number of subjects positive for $U$. urealyticum we identified, a direct consequence of the low number of individuals tested (not a representative population). Nevertheless, this is the first such study carried out in Romania. Further research on a larger population and full access to clinical, epidemiological, and microbiological variables are needed to validate our results.

Our study proposed primer changes and a simpler method making use of devices commonly found in molecular biology laboratories. However, bacterial DNA isolated from biological samples can be subsequently used to determine susceptibility to tetracycline with the proposed technique. Certain DNA amounts can be made available for further determinations e.g. susceptibility to antibiotic resistance as the highly accurate NAATs detection method requires only small DNA amounts.

The high resistance levels reflected in international studies call for continuous surveillance in order to keep track of resistance patterns, limiting the risk of importation. Our results have demonstrated that such resistant strains can occur and need to be detected in order to provide a proper treatment. The early diagnosis and appropriate treatment of $U$. urealyticum may 
prove to be important in reducing infertility or complications caused by this bacterium. Our results indicate that the non-invasive technique we employed can produce quick results both for $U$. urealyticum detection and determination of its resistance to tetracycline using a single easy-tocollect biological sample.

\section{Abbreviations}

STI: Sexually transmitted infection

CDC: Centers for Disease Control and Prevention

NGU: nongonococcal urethritis

PCR: Polymerase chain reaction

PBS: phosphate-buffered saline

CLSI: Clinical and Laboratory Standards Institute

NAAT: nucleic acid amplification test

\section{Authors' contribution}

MLV - Conceptualization, Methodology, Investigation, Validation HVM - Validation, Data Curation, Supervision AK - Investigation, Resources, Writing - original draft preparation

AP - Resources, Writing - review and editing, Data Curation

CAT - Resources, Writing - review and editing, Data Curation

\section{Conflict of Interest Statement}

The authors have no conflicts of interest to declare.

\section{References}

1. World Health Organization. Sexually transmitted infections (STIs). [cited 2020 August 07]; Available from: https:/www.who.int/en/news-room/fact-sheets/detail/ sexually-transmitted-infections-(stis)

2. Grad AI, Vică ML, Ungureanu L, Siserman CV, Tataru AD, Matei HV. Assessment of STI screening in Romania using a multiplex PCR technique. J Infect Dev
Countr. 2020;14(4):341-8. DOI: 10.3855/jidc.11989

3. Grad AI, Șenilă SC, Cosgarea R, Tătaru DA, Vesa SC, Vică ML, et al. Sexual behaviors, attitudes, and knowledge about sexually transmitted infections: A cross-sectional study in Romania. Acta Dermatovenerol Croat. 2018 Apr;26(1):25-32.

4. Waites KB, Katz B, Schelonka RL. Mycoplasmas and ureaplasmas as neonatal pathogens. Clin Microbiol Rev. 2005 Oct;18:757-89. DOI: 10.1128/CMR.18.4.757789.2005

5. Cassell GH, Waites KB, Watson HL, Crouse DT, Harawasa R. Ureaplasma urealyticum intrauterine infection: role in prematurity and disease in newborns. Clin Microbiol Rev. 1993 Jan;6(1):69-87. DOI: 10.1128/ CMR.6.1.69-87.1993

6. Beeton ML, Daha MR, El-Shanawany T, Jolles SR, Kotecha S, Spiller OB. Serum killing of Ureaplasma parvum shows serovar determined susceptibility for normal individuals and common variable immuno-deficiency patients. Immunobiology. 2012 feb;217(2):18794. DOI: 10.1016/j.imbio.2011.07.009

7. Shimada Y, Ito S, Mizutani K, Sugawara T, Seike K, Tsuchiya T, et al. Bacterial loads of Ureaplasma urealyticum contribute to development of urethritis in men. Int J STD AIDS. 2014 Mar;25(4):294-8. DOI: 10.1177/0956462413504556

8. Horner PJ, Donders G, Cusini M, Gomberg M, Jensen JS, Unemo M. Should we be testing for urogenital Mycoplasma hominis, Ureaplasma parvum and Ureaplasma urealyticum in men and women? - a position statement from the European STI Guidelines Editorial Board. J Eur Acad Dermatol Venereol. 2018 Nov;32(11):1845-51. DOI: 10.1111/jdv.15146

9. Stellrecht KA, Worom AM, Mishrik NG, Venezia RA. Comparison of multiplex PCR assay with culture for detection of genital mycoplasmas. J Clin Microbiol. 2004 Apr;42(4):1528-33. DOI: 10.1128/JCM.42.4.15281533.2004

10. Beeton ML, Chalker VJ, Jones LC, Maxwell NC, Spiller OB. Antibiotic resistance among clinical Ureaplasma isolates recovered from neonates in England and Wales between 2007 and 2013. Antimicrob Agents Chemother. 2016 Oct;60(1):52-6. DOI: 10.1128/AAC.00889-15

11. Robertson JA, Coppola E, Heisler OR. Standardized method for determining antimicrobial susceptibility of strains of Ureaplasma urealyticum and their response to tetracycline, erythromycin, and rosaramicin. Antimicrob Agents Chemother. 1981 Jul;20(1):53-8. DOI: 10.1128/aac.20.1.53. DOI: 10.1128/AAC.20.1.53

12. Ford DK, Smith JR. Nonspecific urethritis associated with a tetracycline-resistant T-mycoplasma. Br J Vener Dis. 1974 Oct;50(5):373-4. DOI: 10.1136/sti.50.5.373

13. Stimson JB, Hale J, Bowie WR, Holmes KK. Tetracycline-resistant Ureaplasma urealyticum: a cause of persistent nongonococcal urethritis. Ann Intern Med. 1981 
Feb; 94(2):192-4. DOI: 10.7326/0003-4819-94-2-192 DOI: $10.7326 / 0003-4819-94-2-192$

14. Roberts MC, Kenny GE. TetM tetracyclineresistant determinants in Ureaplasma urealyticum. Pediatr Infect Dis. 1986 Nov-Dec;5(6 Suppl):S338-40. DOI: 10.1097/00006454-198611010-00032

15. Dégrange S, Renaudin H, Charron A, Bébéar C, Bébéar CM. Tetracycline resistance in Ureaplasma spp. and Mycoplasma hominis: prevalence in Bordeaux, France, from 1999 to 2002 and description of two tet(M)-positive isolates of $\mathrm{M}$. hominis susceptible to tetracyclines. Antimicrob Agents Chemother. 2008 Feb;52(2):742-4. DOI: 10.1128/AAC.00960-07

16. Beeton ML, Spiller OB. Antibiotic resistance among Ureaplasma spp. isolates: cause for concern? J Antimicrob Chemother. 2017 Feb;72(2):330-7. DOI: 10.1093/ jac/dkw425

17. Bertram J, Strätz M, Dürre P. Natural transfer of conjugative transposon Tn916 between gram-positive and gram-negative bacteria. J Bacteriol. 1991 Jan;173(2):443-8. DOI: $\quad 10.1128 / J B .173 .2 .443-$ 448.1991

18. Blanchard A, Crabb DM, Dybvig K, Duffy LB, Cassell $\mathrm{GH}$. Rapid detection of tetM in Mycoplasma hominis and Ureaplasma urealyticum by PCR: tetM confers resistance to tetracycline but not necessarily to doxycycline. FEMS Microbiol Lett. 1992 Aug; 74(2-3):27781. DOI: 10.1111/j.1574-6968.1992.tb05379.x

19. Meygret A, Le Roy C, Renaudin H, Bébéar C, Pereyre $\mathrm{S}$. Tetracycline and fluoroquinolone resistance in clinical Ureaplasma spp. and Mycoplasma hominis isolates in France between 2010 and 2015. Journal of Antimicrob Chemother. 2018 Oct;73(10):2696-703. DOI: $10.1093 / \mathrm{jac} / \mathrm{dky} 238$

20. Valentine-King MA, Brown MB. Antibacterial resistance in Ureaplasma species and Mycoplasma hominis isolates from urine cultures in college-aged females. Antimicrob Agents Chemother. 2017 Oct;61(10):e01104-17. DOI: 10.1128/AAC.01104-17

21. Beeton ML, Chalker VJ, Maxwell NC, Kotecha S, Spiller OB. Concurrent titration and determination of antibiotic resistance in ureaplasma species with identification of novel point mutations in genes associated with resistance. Antimicrob Agents Chemother. 2009 May;53(5):2020-7. DOI: 10.1128/AAC.01349-08

22. Vică ML, Junie L, Grad AI, Tătaru DA, Matei HV. Determination of sexually transmitted diseases frequency by simultaneous detection of six pathogens using PCR methods. J Environ Prot Ecol. 2015;16(4):1603-11.

23. Vică ML, Junie L, Grad AI, Tătaru DA, Matei HV. Distribution of sexually transmitted diseases in a group of symptomatic male patients using urine samples and PCR technique. Rev Romana Med Lab. 2015 Sep;23(3):323-31. DOI: 10.1515/rrlm-2015-0029

24. Govender S, Chalkley L. Tetracycline resis- tance genes of ureaplasmas. South Afr J Epidemiol Infect. 2012;27(1):19-23. DOI: 10.1080/10158782.2012.11441475

25. Toyer AL, Trignol-Viguier N, Mereghetti L, Joly B, Blin E, Body G, et al. Interest of simultaneous Chlamydia trachomatis and Neisseria gonorrhoeae screening at the time of preabortion consultation. Contracept. 2012 Nov;86(5):572-6. DOI: 10.1016/j.contraception.2012.04.012

26. Nemescu RE, Ursu RG, Dorobăț CM, Iancu LS. The efficiency of sodC gene / N. meningitidis detection in comparison with the classical methods for the diagnosis of meningococcal infection. Rev Romana Med Lab. 2015 Mar;23(1):21-30. DOI:10.1515/rrlm-2015-0008 DOI: $10.1515 / \mathrm{rrlm}-2015-0008$

27. O'Byrne P. Self-directed sexually transmitted infection testing: providing noninvasive sexual health services. Appl Nurs Res. 2011 Feb;24(1):17-21. DOI: 10.1016/j. apnr.2009.02.005

28. Zhang N, Wang R, Li X, Liu X, Tang Z, Liu Y. Are Ureaplasma spp. a cause of nongonococcal urethritis? A systematic review and metaanalysis. PLoS One. 2014 Dec; 9(12):e113771. DOI: 10.1371/journal. pone. 0113771

29. Blanchard A, Barile MF. Cloning of Ureaplasma urealyticum DNA sequences showing genetic homology with urease genes from gram-negative bacteria. Res Microbiol. 1989 May-Jun;140(4-5):281-90. DOI: 10.1016/0923-2508(89)90020-X

30. Roberts MC, Kenny GE. Dissemination of the tetM tetracycline resistance determinant to Ureaplasma urealyticum. Antimicrob Agents Chemother. 1986 Feb;29(2):350-2. DOI: 10.1128/AAC.29.2.350

31. Brown JT, Roberts MC. Cloning and characterization of tetM gene from a Ureaplasma urealyticum strain. Antimicrob Agents Chemother. 1987 Nov;31(11):1852-4. DOI: 10.1128/AAC.31.11.1852

32. Mardassi BBA, Aissani N, Moalla I, Dhahri D, Dridi A, Mlik B. Evidence for the predominance of a single tet $(\mathrm{M})$ gene sequence type in tetracycline resistant Ureaplasma parvum and Mycoplasma hominis isolates from Tunisian patients. J Med Microbiol. 2012 Sep;61(9):1254-61. DOI: 10.1099/jmm.0.044016-0

33. Burdett V. Purification and characterization of Tet(M), a protein that renders ribosomes resistant to tetracycline. J Biol Chem. 1991 Feb;266(5):2872-7

34. Taraskina AE, Savicheva AM, Akopian TA, Soroka AE, Momynaliev KT, Govorun VM. Drift of tetM Determinant in Urogenital Microbiocenosis Containing Mycoplasmas during Treatment with a Tetracycline Antibiotic. Bull Exp Biol Med. 2002;134(1):60-3. DOI: 10.1023/A:1020664807029

35. Ikonomidis A, Venetis C, Georgantzis D, Giaslakiotis V, Kolovos V, Efstathiou K, et al. Prevalence of Chlamydia trachomatis, Ureaplasma spp., Mycoplas- 
ma genitalium and Mycoplasma hominis among outpatients in central Greece: absence of tetracycline resistance gene tet(M) over a 4-year period study. New Microbes New Infect. 2016 Jan;9:8-10. DOI: 10.1016/j. nmni.2015.11.005

36. Redelinghuys MJ, Ehlers MM, Dreyer AW, Lombaard HA, Kock MM. Antimicrobial susceptibility patterns of Ureaplasma species and Mycoplasma hominis in pregnant women. BMC Infect Dis. 2014 Mar;14:171. DOI: 10.1186/1471-2334-14-171

37. Diaz L, Cabrera LE, Fernandez T, Ibá-ez I, Torres Y, Obregón Y, et al. Frequency and antimicrobial sensitivity of Ureaplasma urealyticum and Mycoplasma homi- nis in patients with vaginal discharge. MEDICC Rev. 2013 Oct;15(4):45-7

38. Kotrotsiou T, Exindari M, Diza E, Gioula G, Melidou A, Malisiovas N. Detection of the tetM resistance determinant among phenotypically sensitive Ureaplasma species by a novel real-time PCR method. Diagn Microbiol Infect Dis. 2015 Feb;81(2):85-8. DOI: 10.1016/j. diagmicrobio.2015.02.012

39. Boujemaa S, Mlik B, Ben Allaya A, Mardassi H, Ben Abdelmoumen Mardassi B. Spread of multidrug resistance among Ureaplasma serovars, Tunisia. Antimicrob Resist Infect Control. 2020 Jan;9:19. DOI: 10.1186/ s13756-020-0681-5 